\title{
A STUDY ON SUPRA ORBITAL FORAMINA IN HUMAN SKULL
}

Bilodi A K S ${ }^{1}$, Gupta S $\mathbf{C}^{1}$, Saxena R $\mathrm{C}^{1}$

\begin{abstract}
In the Anatomy department of Ncpalgunj Medical College, Nepal 51 adult human skulls were studied regarding supra orbital foramen. Various types or combination of supra orbital foramen, supra orbital notch, double foramina, double notch, incomplete foramen, absence of all above. Their number \& percentage were calculated both on right and left side separately, compared \& correlated with other studies.
\end{abstract}

\section{Key Words: Supra orbital foramen, Supra orbital notch, Supra orbital ligament, Periosteal ligament.}

\section{INTRODUCTION}

Supra orbital foramen is an osseous opening present in norma frontalis along with infra orbital foramen and mental foramen which lie in vertical line that passes between premolar teeth sagitally on both sides. The above openings transmit supra orbital nerves and vessels, infra orbital nerves and vessels, mental nerves and vessels respectively. Supra orbital notch is some times bridged by periosteal ligament. This ligament undergoes ossification in $25 \%$ of cases as described by Duke Elder which named it as Supra Orbital Ligament. ${ }^{1}$ Sinha observed combinations of 14 types of supra orbital foramen. ${ }^{2}$ Rao et al described 24 types combinations of supra orbital foramen in 200 human skulls. ${ }^{3}$ The aim of the present study is to know various combinations of supra orbital foramina in Nepalese skulls.

1. Nepalgunj Medical College, Chisapani, Banke, Nepal.

Address for correspondence : Dr. Arun Kumar S. Bilodi

Associate Professor of Anatomy

Nepalgunj Medical College, Chisapani, Banke, Nepal

Email: chisapani@hotmail.com

JNMA, October - December, 2002, 41 
MATERIAL \& METHODS

Fifty-one dry adult human skulls were examined from the Anatomy Department of Nepalgunj Medical College, Chisapani. Banke, Nepal. The above skulls were examined for various combinations of supra orbital foramina. Their number and percentages recorded and compared with other workers.

Table I : Comparison of the various types of combinations of supra orbital foramina(Notch) in the present study with those of Rao et al $(1997)^{3}$

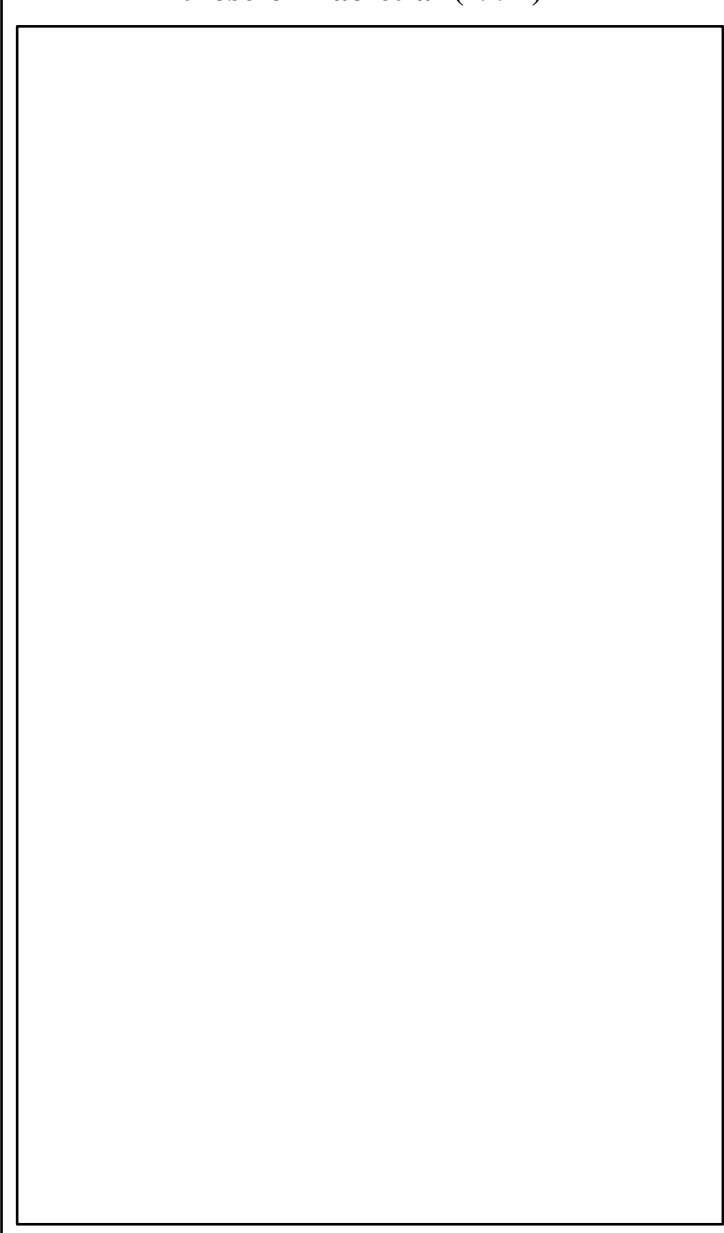

\section{Abbreviations}

$\mathrm{F}=$ Supra orbital foramen, $\mathrm{N}=$ Supra orbilal notch, $\mathrm{DF}=$ Double foramen. $\mathrm{IF}=$ Incomplete Foramen $\mathrm{DN}=$ Double notch, $\mathrm{X}=$ Absence of supra orbital foramen, $\mathrm{MF}=$ multiple foramina.

\section{OBSERVATION AND DISCUSSION}

In the present study various types of combinations supra orbital foramina were observed as given in table I.

The above table shows the presence of multiple foramina in our study in $7.84 \%$ of cases on left side but Rao et al did not report this combination. Some of the combinations reported in this study were not observed by Rao et al or vice versa. This difference in the various types of combinations may be due to either material difference or population difference. Our study is based on Nepalese crania while Rao et al worked on South Indian skulls.

Table II : Different types of foramen

\section{SUPRAORBITAL FORAMINA}

Duke Elder and Hollinshed ${ }^{4}$ reported supra orbital foramina in $25 \%$ of total skulls. Rao et al ${ }^{3}$ reported it only in $6.5 \%$ of South Indian skulls. Berry reported equal occurrence of supra orbital foramina and supra orbital notch in the Mexicans crania.

In the present study, we observed supra-orbital foramina in $31.37 \%$ of cases on right side and $17.64 \%$ of cases on left side. This shows the occurrence of supra orbital foramina in Nepali crania is higher than South Indian population.

\section{SUPRAORBITAL NOTCHES}

Sinha observed occurrence of supra orbital notches in $44.25 \%$ of total skulls as common feature. ${ }^{2}$ 


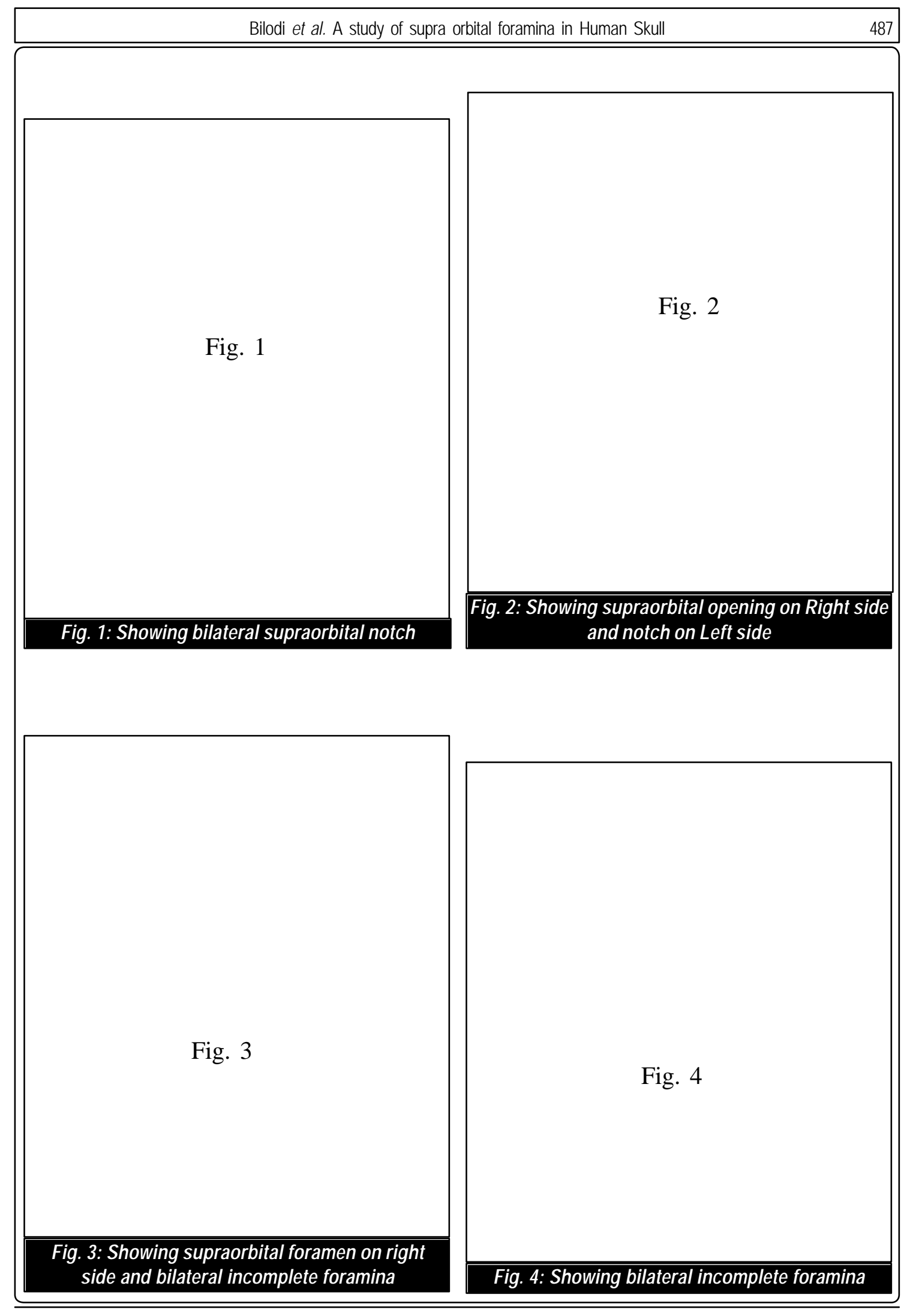

JNMA, October - December, 2002, 41 
In the present study supra orbital notches were present in $37.25 \%$ of cases on right side and in $33.33 \%$ of cases on left side which is in resemblance with observations of Rao et al $(38.5 \%))^{3}$

In the present study, we did not find second notch of Arnold as reported by Duke. ${ }^{1}$ Warwick et al. ${ }^{6}$

\section{CONCLUSION}

This study gives us the knowledge of various combinations of supra orbital foramina in same skull. It also gives comparison of number of percentages of supra orbital foramina in different skulls. The very presence of supra orbital foramina (notch) will give protection to supra orbital vessels and nerves where as absences supra orbital foramina (notch) may injure the nerves and vessels due to sharp margin of the orbital rim.

\section{ACKNOWLEDGEMENT}

I am highly grateful to Managing Director \& Director of Lord Buddha Educational Academy, Nepalgunj, and Principal of NepalgunJ Medical College for allowing to use the materials from the
Department of Anatomy. Sincere thanks to Library and Computer Staff providing technical help for using material from the Library and preparing the manuscript.

\section{REFERENCES}

1. D uke E Ider S.S - S ystem of 0 pthal mology $1^{\text {st }}$ edition volume I I , 1961, 401.

2. Sinha $D N ; S$ tudy of $S$ upra $O$ rbital $N$ otch $\& F$ oramen in $\mathrm{N}$ orth I ndian H uman S kulls - J ournal of A natomical Society of I ndia, 1978, 27 : 124-126.

3. $R$ ao $S$ udha, Shaligram, $R$ ao $V$ asudev $A$ nand, $C$ helvakumaran T .S et. al., $S$ tudy of supra orbital $\mathrm{N}$ otch and Foramen in $200 \mathrm{H}$ uman skulls in south I ndia, A natomical A djuncts, 1997, V ol. 2 N 03,15 22.

4. H ollinshed W. H enry in A natomy for S urgery $V$ ol. | P | | | 1966.

5. B erry A C - F actors affecting the I ncidence of nonM usculo S kel etal V ariant. J. A natomy, 1975, 120: 519: 535.

6. W arwick, W illiams, D yson, B annister. G ray's A natomy, $E$ L B S, C hurchill living $S$ tone, $37^{\text {th }}$ edition, 1992, 343. 